\title{
Rancang Bangun Sistem Pengelolaan Berkas Pengajuan Kenaikan Pangkat Pegawai Pada Dinas Perhubungan Kabupaten Sorong Berbasis Web
}

\author{
Nirwana Nurdjan ${ }^{1}$, Denny Yapari ${ }^{2}$, Tri Wahyu Kurnia Ningsih ${ }^{3}$ \\ Program Studi Teknik Informatika, Universitas Muhammadiyah Sorong \\ E-mail: ${ }^{1}$ nirwana@um-sorong.ac.id, ${ }^{2}$ denny.yapari@gmail.com, ${ }^{3}$ triwahyukurnia@gmail.com
}

\begin{abstract}
Abstrak
Salah satu syarat kenaikan pangkat pegawai pada Dinas Perhubungan Kabupaten Sorong yaitu dengan memasukkan berkas berkas pegawai. Dalam proses kenaikan pangkat pegawai harus nmemasukan berkas berupa berkas fisik seperti fotocopy kartu pegawai elektrik PNS, fotocopy surat keterangan atasan langsung, fotocopy surat kenaikan pangkat terakhir, fotocopy ijazah terakhir, fotocopy SK, fotocopy surat sasaran kinerja pegawai dan sebagainya yang dibutuhkan sesuai pangkatnya untuk memenuhi persyaratan kenaikan pangkat.Namun jika, proses pengajuan kenaikan pangkat masih berupa berkas fisik maka pencarian,pengelolaan,dan penyimpanan akan terjadi penumpukan.

Sehingga tujuan dari penelitian ini adalah untuk membuat sebuah sistem pengelolaan berkas pengajuan kenaikan pangkat pegawai pada Dinas Perhubungan Kabupaten Sorong berbasis web, agar memudahkan pegawai memasukan berkas persyaratan tanpa berupa berkas fisik,dan bisa diakses dimana saja dan kapan saja melalui website.
\end{abstract}

Kata kunci : Sistem Pengelolaan Berkas Kenaikan Pangkat Pegawai, Website, Metode Waterfall

\section{PENDAHULUAN}

$\mathrm{K}$ enaikan pangkat pegawai adalah penghargaan yang diberikan atas prestasi kerja dan pengabdian Pegawai Negeri Sipil terhadap Negara, serta sebagai dorongan kepada Pegawai Negeri Sipil untuk lebih meningkatkan prestasi kerja dan pengabdiannya. Setiap pegawai berhak mengajukan pengusulan kenaikan pangkat sesuai dengan jabatan dan golongannya.

Dalam proses pengelolaan berkas usul pegawai yang akan mengajukan kenaikan pangkat pada Dinas Perhubungan Kabupaten Sorong masih menggunakan sistem manual seperti memasukan berkas berupa fotocopy kartu pegawai elektrik pns, fotocopy sah kenaikan pangkat terakhir, fotocopy sasaran kinerja pegawai, fotocopy surat keterangan atasan langsung, fotocopy surat diklat, fotocopy ijazah terakhir, fotocopy sah sk cpns atau sk pns, fotocopy daftar riwayat hidup dalam memberikan informasi yang masih berupa berkas fisik, pencarian, pengelolaan, dan penyimpanan data pegawai masih disimpan dalam bentuk arsip, sehingga terjadinya penumpukan data. Berkas tersebut jumlahnya sangat banyak dan bertumpuk menjadi satu, sehingga apabila dilakukan pencarian suatu data akan membutuhkan waktu yang lama dan dapat memperlambat pelaksanaan pengajuan berkas usul kenaikan pangkat pegawai. Proses tersebut dapat membuat suatu kekeliruan, maka perlu dibuat sistem pengolahan berkas pengajuan kenaikan pangkat berbasis web yang dapat mengatur proses kenaikan pangkat dan mempercepat 
dalam waktu pengajuan berkas pengajuan pegawai yang akan melakukan proses kenaikan pangkat.

Oleh karena itu,peneliti bermaksud mengangkat permasalahan tersebut kedalam tugas akhir skripsi dengan judul " RANCANG BANGUN SISTEM PENGELOLAAN BERKAS PENGAJUAN KENAIKAN PANGKAT PEGAWAI PADA DINAS PERHUBUNGAN KABUPATEN SORONG BERBASIS WEB $"$.

\section{METODE PENELITIAN}

\subsection{Kenaikan Pangkat Pegawai}

Kenaikan pangkat pegawai adalah penghargaan yang diberikan atau prestasi kerja dan pengabdian pegawai negeri sipil terhadap negara, serta sebagai dorongan kepada pegawai negeri sipil untuk lebih meningkatkan prestasi kerja dan pengabdiannya.

\section{2 Website}

Website merupakan kumpulan dari halaman-halaman web yang berhubungan dengan file-file lain yang terkait. Dalam sebuah website terdapat suatu halaman yang dikenal dengan sebutan home page. Home page adalah sebuah halaman yang pertama kali dilihat ketika seseorang mengunjungi website.

\section{3 HTML}

$H T M L$ adalah suatu format data yang digunakan untuk membuat dokumen hypertext yang dapat dieksekusi dari satu platform ke platform komputer lainnya tanpa perlu melakukan suatu perubahan apapun dengan suatu alat tertentu.

\section{4 PHP}

$P H P$ adalah kode/skrip yang akan dieksekusi pada server side. Skrip $P H P$ akan membuat suatu aplikasi dapat di-integrasikan ke dalam $H T M L$, sehingga suatu halaman web tidak lagi bersifat statis, namun menjadi bersifat dinamis. Sifat server side berarti pengerjaan skrip dilakukan di server, baru kemudian hasilnya dikirimkan ke browser. PHP juga menyediakan fungsi-fungsi siap pakai untuk berbagai keperluan, seperti memanipulasi string, tanggal, file dan lain-lain.

\section{2. $5 M Y S Q L$}

$M y S Q L$ sebenarnya merupakan turunan dari salah satu konsep utama dalam basis data sejak lama, yaitu SQL (Structured Query Language). SQL adalah sebuah konsep pengoperasian basis data terutama untuk proses seleksi, pemasukan, pengubahan dan penghapusan data yang dimungkinkan dapat dikerjakan dengan mudah dan otomatis.

\section{6 CSS ( Cascading Style Sheet)}

CSS adalah suatu bahasa style sheet yang digunakan untuk mengatur tampilan suatu dokumen yang ditulis dalam bahasa markup. Penggunaan yang paling umum dari CSS adalah untuk memformat halaman web yang ditulis dengan $H T M L$ dan XHTML. Walaupun demikian, bahasanya sendiri dapat dipergunakan untuk semua jenis dokumen $X M L$ termasuk $S V G$ dan $X U L$.

\section{7 PHP MyAdmin}

PhpMyAdmin merupakan bagian untuk mengelola basis data MySql yang ada dikomputer. Untuk membukanya, buka browser lalu ketik alamat http://localhostphpmyadmin, maka akan muncul halaman phpMyAdmin. 


\section{8 Хатрр}

$X A M P P$ merupakan paket $P H P$ berbasis open source yang dikembangkan oleh sebuah komunitas Open Source, dengan menggunakan XAMPP kita tidak perlu melakukan penginstalan program yang lain karena semua kebutuhan telah disediakan oleh XAMPP. Beberapa paket yang telah disediakan adalah Apache, MySQL, PHP, Filezilla dan Phpmyadmin.

\section{HASIL DAN PEMBAHASAN}

\subsection{Lokasi Tempat Penelitian}

Lokasi yang dijadikan tempat penelitian yaitu Dinas Perhubungan kabupaten sorong yang beralamat di:

Lokasi Kantor : Dinas Perhubungan Kabupaten Sorong Km. 24

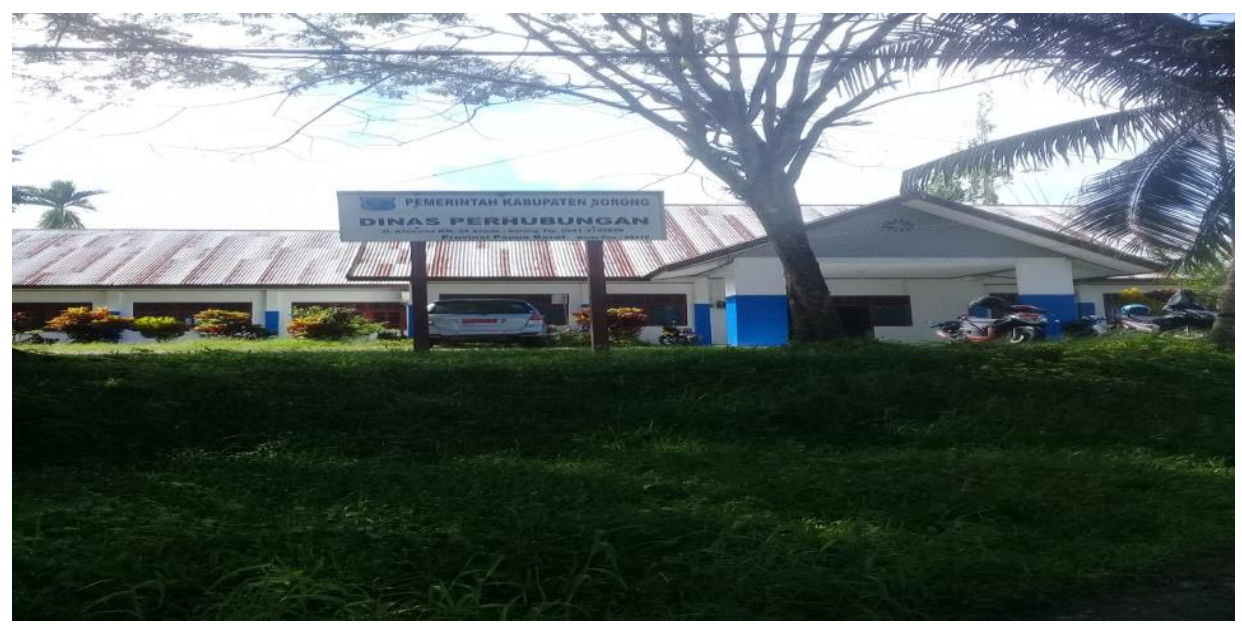

Gambar 1 Lokasi Dinas Perhubungan Kabupaten Sorong

\subsection{Metode Perancangan Sistem}

Metode yang digunakan penulis dalam perancangan aplikasi ini adalah metode

Waterfall. Tahapan metode waterfall dapat dilihat pada gambar 2.

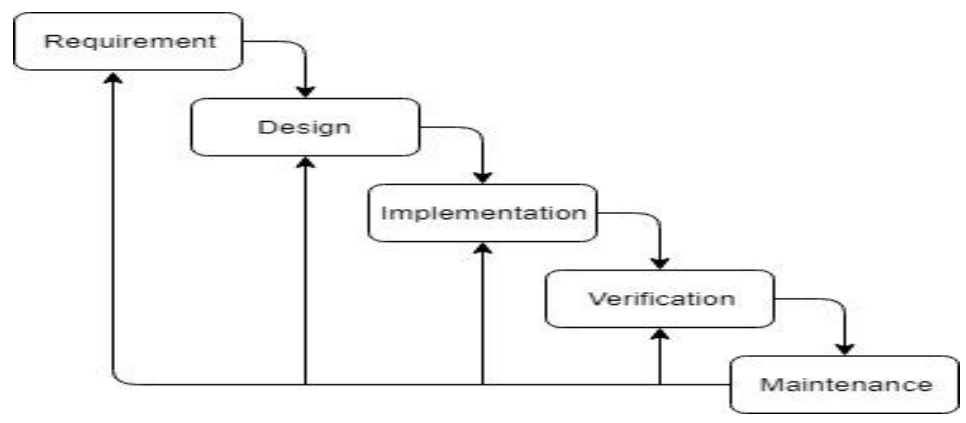

Gambar 2 Waterfall

\subsection{Desain Unified Modeling Language (UML)}

Desain UML yang digunakan meliputi beberapa diagram yaitu diagram usecase dan ERD (Entity Relationship Diagram). 
a. Usecase

Berikut ini adalah Use Case dari sistem pengelolaan berkas pengajuan kenaikan pangkat pegawai.

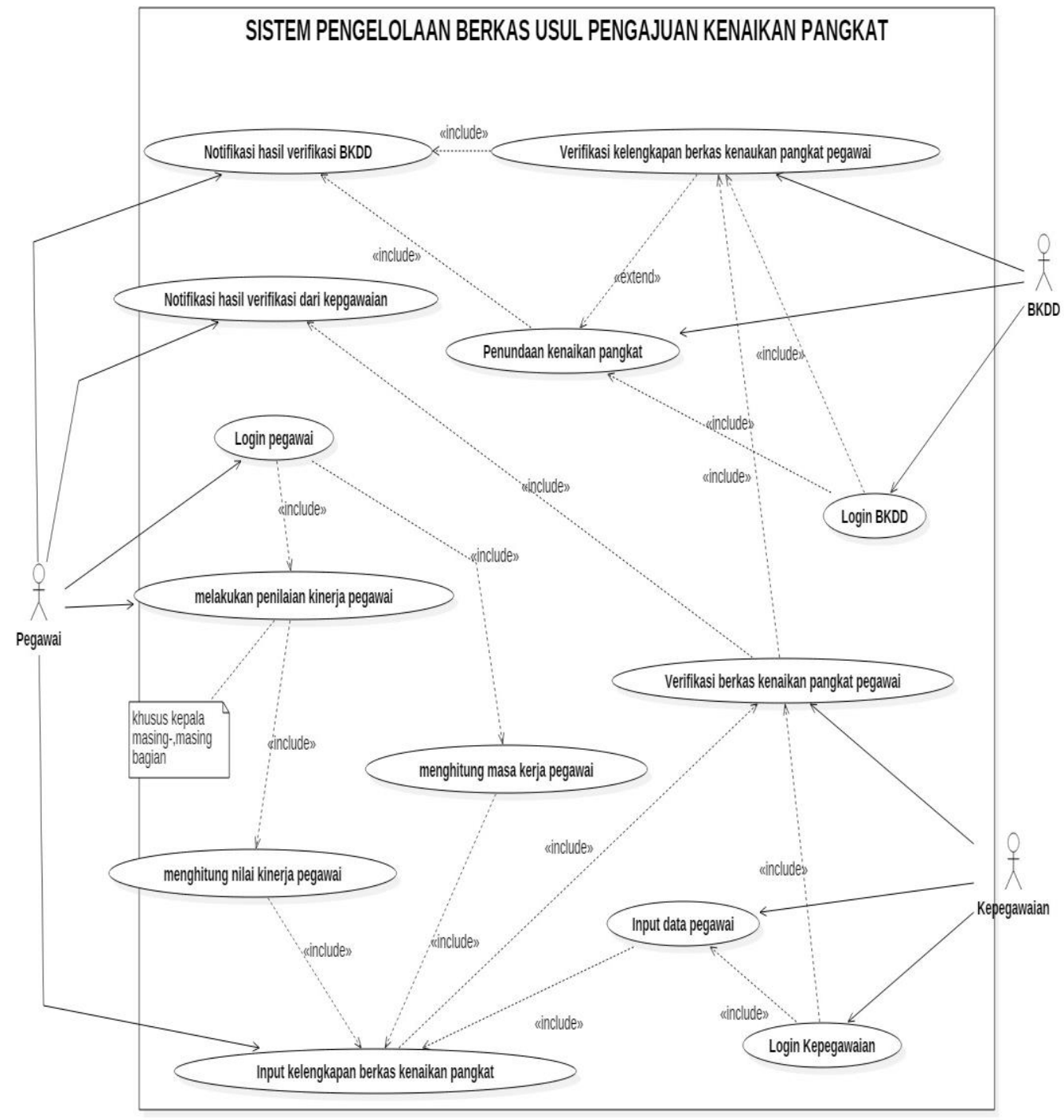

Gambar 3 Usecase

b. ERD (Entity Relationship Diagram)

Berikut adalah ERD ( Entity Relationship Diagram ) dari pengelolaan berkas pengajuan kenaikan pangkat pegawai. 


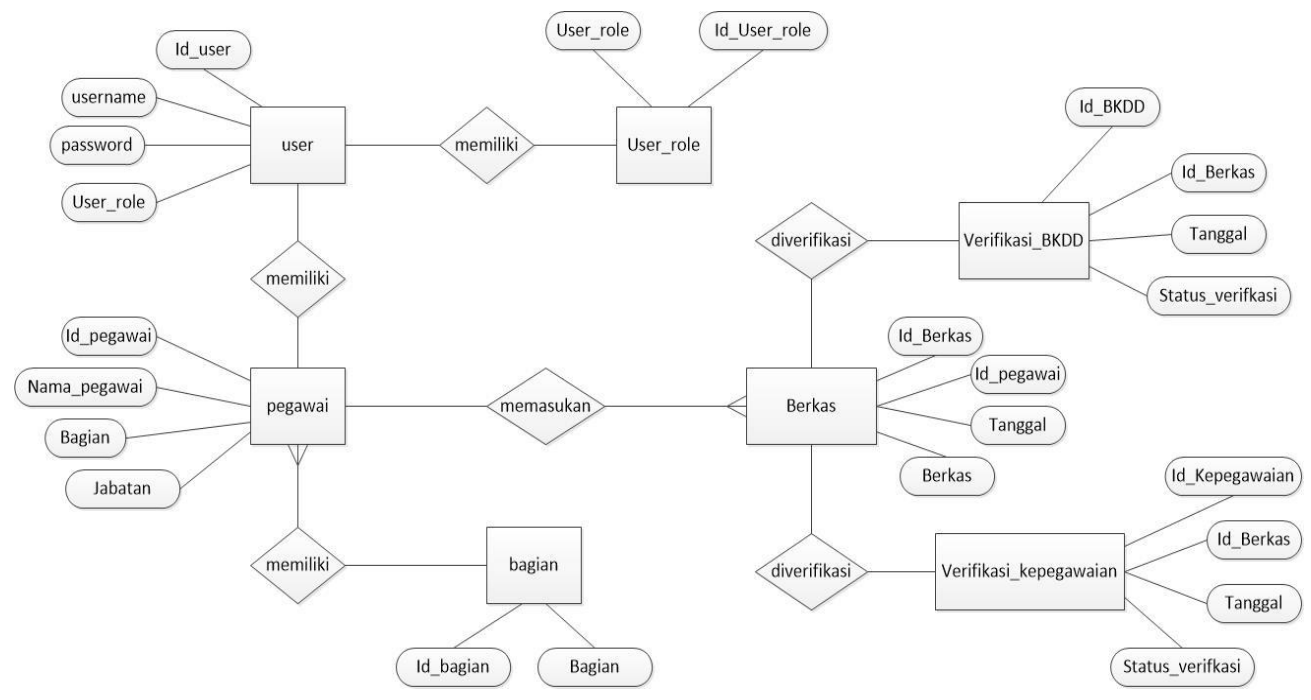

Gambar 4 ERD ( Entity Relationship Diagram )

\subsection{Implementasi}

Dibawah ini merupakan implementasi Interface tampilan fitur fitur pada sistem pengelolaan berkas pengajuan kenaikan pangkat pegawai pada dinas perhubungan kabupaten sorong berbasis web.

a. Halaman Login

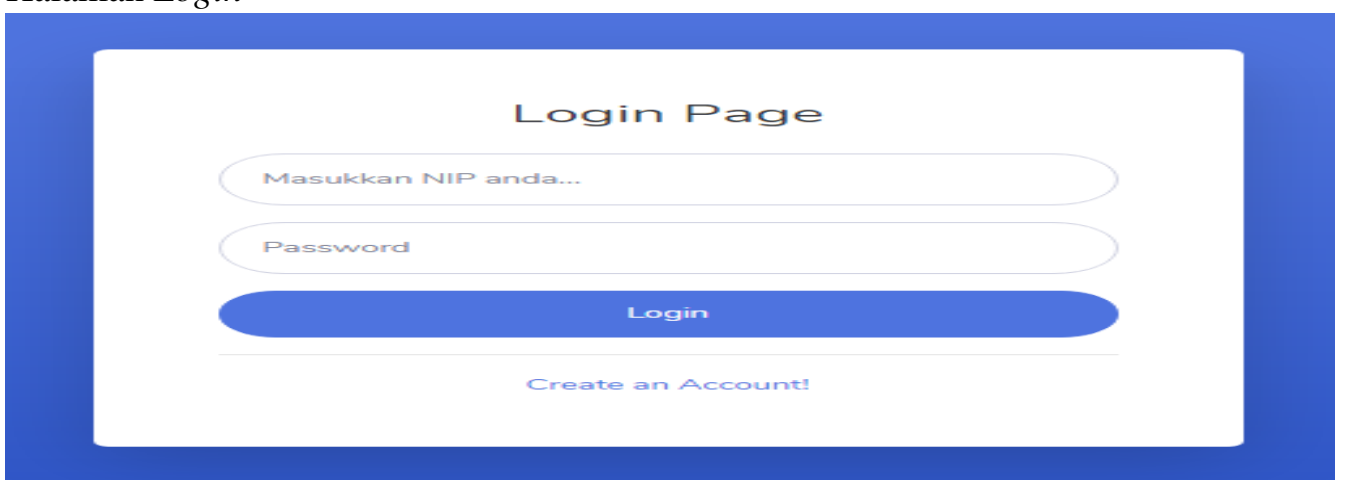

Gambar 5 halaman login

b. Halaman beranda pegawai

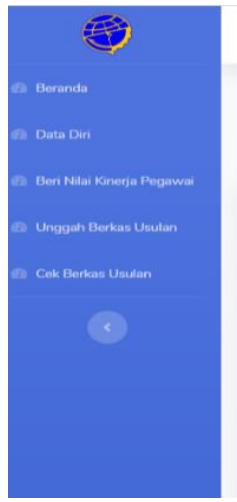

Beranda

Anda Belum Meng-unggah berkas usulan kenaikan pangkatt Unggah Sekarans

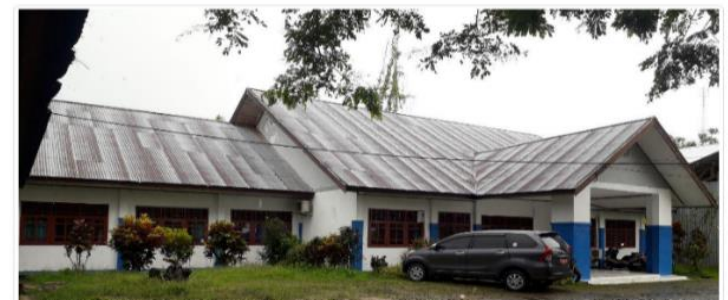

Gambar 6 halaman beranda pegawai 
c. Halaman data diri pegawai

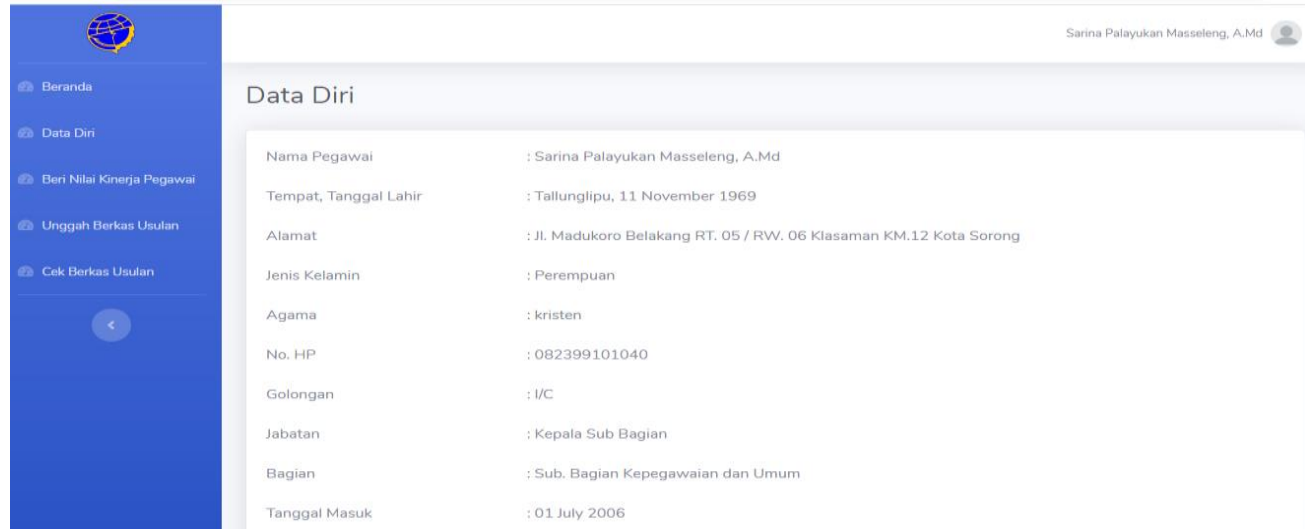

Gambar 7 Halaman data diri pegawai

d. Halaman unggah berkas pegawai

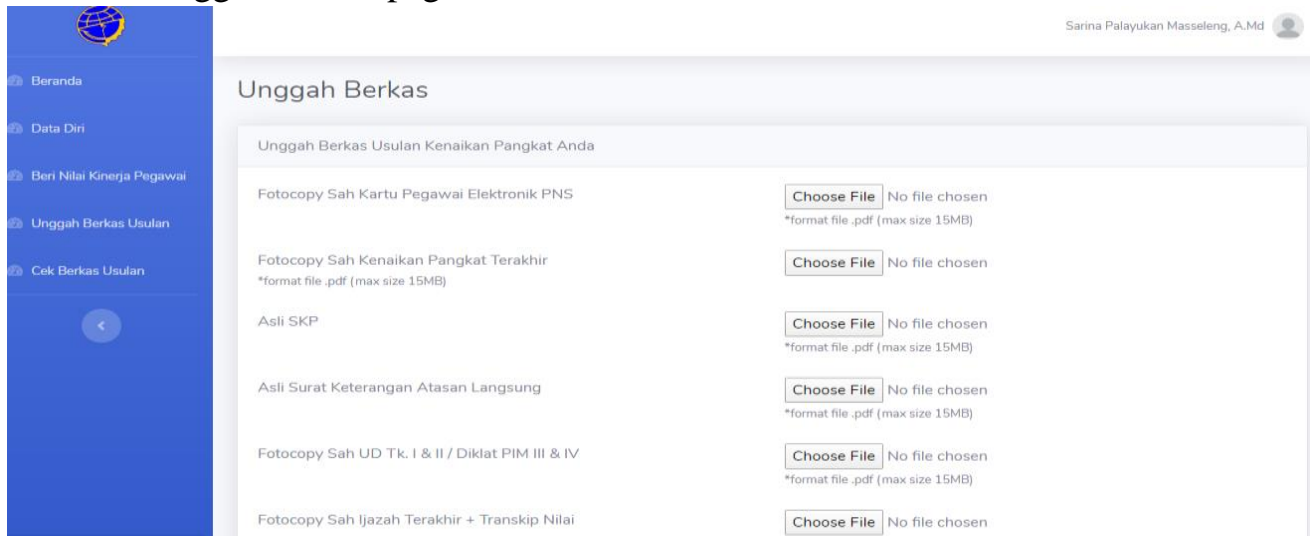

Gambar 8 Halaman unggah berkas pegawai

e. Halaman beranda kepegawaian

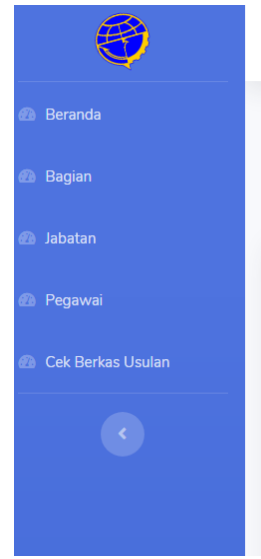

Beranda

Anda mempunyai 7 pegawai yang belum dievaluasi kinerjanyal Lihat Sekarang

Update Informasi

Heading $3 \vee$ B $I$ O : : ${ }_{2}=$ 至

Kementerian Perhubungan Republik Indonesia

Kementerian Perhubungan Republik Indonesia (disingkat Kemenhub RI) adalah kementerian dalam Pemerintah Indonesia yang membidangi urusan transportasi. Kemenhub dipimpin oleh seorang Menteri Perhubungan (Menhub) yang sejak tangga 27 Juli 2016 dijabat oleh Budi Karya Sumadi.

Gambar 9 Halaman beranda kepegawaian 
f. Halaman data pegawai kepegawaian

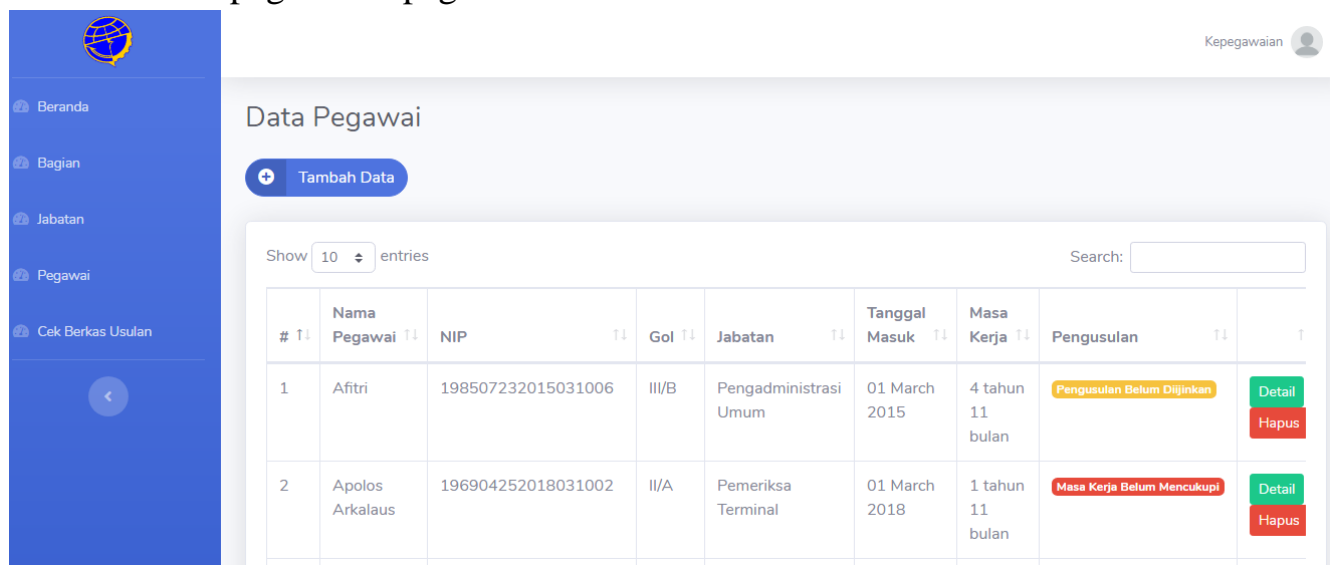

Gambar 10 Halaman data pegawai kepegawaian

g. Halaman verifikasi berkas usulan pegawai kepegawaian

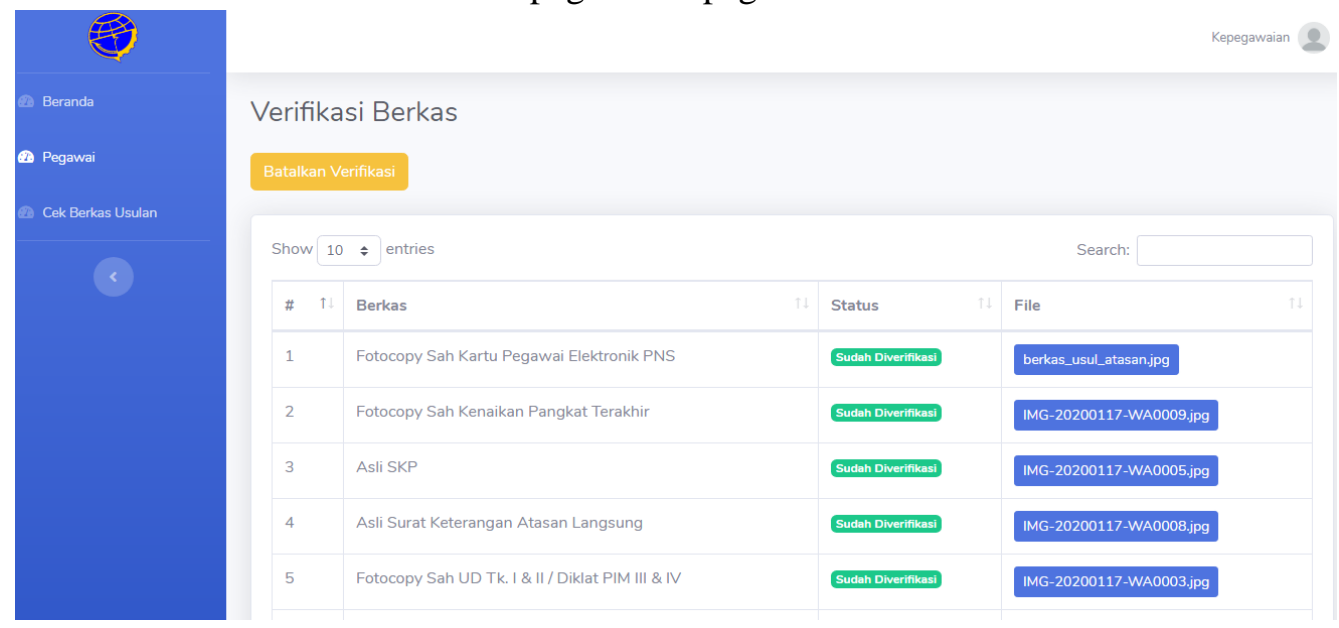

Gambar 11 Halaman verifikasi berkas usulan pegawai kepegawaian

h. Halaman beranda BKDD

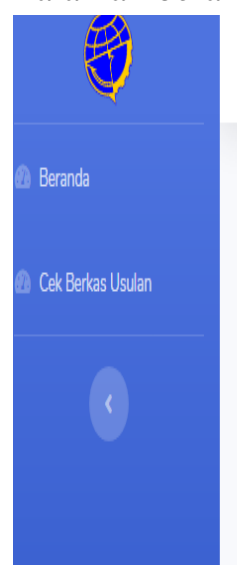

Beranda

Anda mempunyai 1 usulan kenaikan pangkat yang belum diverfikasil Lihat Sekarang

Gambar 12 Halaman beranda BKDD 
i. Halaman verifikasi dan penundaan pegawai BKDD

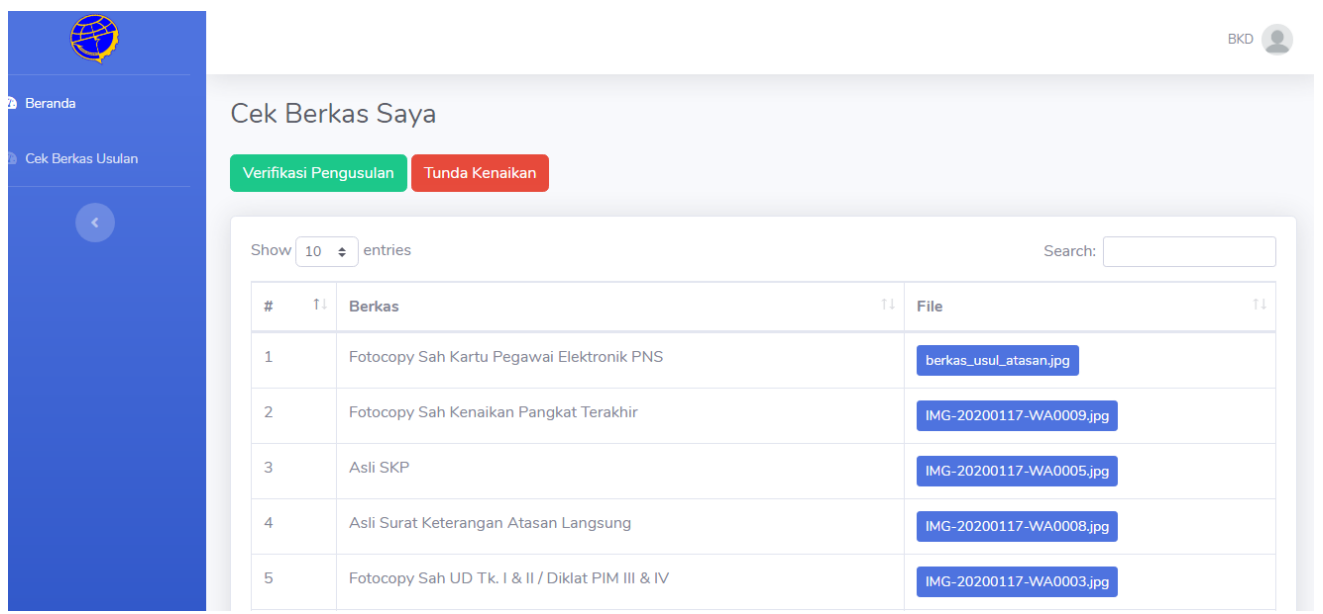

Gambar 13 Halaman verifikasi dan penundaan BKDD

\section{KESIMPULAN}

Berdasarkan hasil penelitian yang telah dilakukan dapat disimpulkan beberapa hal sebagai berikut :

1. Dalam perancangan dan pembuatan aplikasi web pengelolaan berkas pengajuan kenaikan pangkat pegawai pada dinas perhubungan, penerapan metode pengembangan sistem waterfall menjadi sangat efektif mengingat fleksibilitas dalam tahapan pengembangan yang menunjang dalam pengerjaan web.

2. Pemanfaatan web dalam sistem pengarsipan berkas pengajuan kenaikan pangkat pegawai dapat mempermudah proses pengarsipan berkas yang semula berupa fisik kertas, yang kemudian menjadi penyimpanan yang terkomputerisasi.

\section{SARAN}

1. penelitian ini masih berfokus pada sistem pengelolaan berkas berbasis web, dan disarankan agar penelitian ini dapat dikembangkan dalam penerapan sistem Sasaran Kinerja Pegawai berbasis online sehingga web ini dapat menjadi lebih baik lagi.

2. Penyempurnaan tampilan antarmuka aplikasi agar kedepannya menjadi lebih baik dan menarik lagi.

\section{UCAPAN TERIMA KASIH}

Syukur tak lupa saya panjatkan kehadirat Allah SWT atas ridho-Nya lah penelitian ini dapat dilaksanakan, kemudian penulis tak lupa mengucapkan terimakasih kepada kedua orang tua yang telah mensupport dan mendoakan penulis agar diberikan kemudahan dalam menyelesaikan penelitian ini dan terakhir penulis juga tak lupa mengucapkan terima kasih kepada semua pihak yang memberi dukungan sehingga penelitian ini dapat diselesaikan. 


\section{DAFTAR PUSTAKA}

[1] Berri Muzzakir, Inayatullah, Triana Elizabeth . ( 2011 ) . Racang Bangun Sistem Informasi Perhitungan Kredit Poin Pengajuan Jenjang Jabatan Akademik Dosen Pada STMIK GI MDP Palembang. Palembang.

[2] Ema Selvarosa, Qorinta Shinta . ( 2014 ). Perancangan Sistem Kearsipan Dokumen Kepangkatan Dokter Spesialis ( Studi Kasus Di RS Dr. Kariadi Bagian Anestesi ) . Semarang.

[3] Gilaand, A . ( 2016 ). Pathology of Faculty Memebers' rank Promotion in Universities and Higher Educations Institutions Affiliated to The Ministry of Health and Medical Education of The Islamic Republic of Iran. Int J Med Res Health Sci, 5 ( 9S ),25 - 30.

[4] Harianto, Akhmad Zulkifli, Yulanda . ( 2017 ) . Aplikasi Penilaian Angka Kredit Dosen Untuk Proses Pengajuan Jabatan Fungsional ( Studi kasus : STMK Hang Tuah Pekanbaru ) . Pekanbaru . Jurnal Ilmu Komputer.

[5] Hannar Kremer, Isabel Vilmor, Herman Aqunis . ( 2019 ) . Innovation Leadership: BestPractice recommendations for promoting employee creativity, voice, and knowledge sharing. Indiana University.

[6] Marini . ( 2017 ), Rancang Bangun Sistem Informasi Kenaikan Pangkat Pada Kantor Kecamatan Bukit Intan. Pangkal Pinang.

[7] Mahni Pitriyanti, Khairul Imtihan . ( 2018 ). Sistem Informasi Kenaikan Pangkat Karyawan Pada Dinas Pekerjaan Umum ( PU ) dan Energi Sumber Daya Mineral ( ESDM ) Kabupaten Lombok Tengah . Lombok Tengah . Jurnal Manajemen Informatika dan Sistem Informasi.

[8] Mirza Abdillah, Haerudin, Bambang Cahyono . ( 2017 ). Sistem Informasi Penerimaan Berkas Usul Kenaikan Pangkat Pada Badan Kepegawaian Daerah Kabupaten Kutai Kartanegara . Samarinda.

[9] Ridwan Setiawan, Syehabbudin Arief Aisahed . ( 2018 ). Rancangan Perangkat Lunak Aplikasi Kenaikan Jabatan Fungsional Dosen . Garut.

[10] Uslifatul Ustaniah . ( 2018 ). Sistem Informasi Pengajuan Kenaikan Jabatan Fungsional Dosen Menggunakan Pedoman Angka Kredit Kenaikan Pangkat Jabatan Akademik Dosen Jember.

[11] Soekarta, R. (2015). Rancang Bangun Sistem Informasi Akademik Berbasis Web (Studi Kasus Universitas Muhammadiyah Sorong). Insect (Informatics and Security): Jurnal Teknik Informatika, 1(1), 1-8. 